J. Electroanal. Chem., 265 (1989) 67-75

Elsevier Sequoia S.A., Lausanne - Printed in The Netherlands

\title{
Scanning tunneling microscopy of amorphous alloy electrocatalysts for water electrolysis
}

\author{
G. Kreysa
}

DECHEMA, Theodor-Heuss-Allee 25, 600 Frankfurt am Main 97 (F.R.G.)

\section{J. Gomez and A. Baró}

Departamento de Fisica Fundamental, Facultad de Ciencias, Universidad Autónoma de Madrid, Canto Blanco, Madrid 34 (Spain)

\section{A.J. Arvia}

Instituto de Investigaciones Fisicoquimicas Teóricas y Aplicadas (INIFTA), Facultad de Ciencias Exactas, Universidad Nacional de La Plata, Casilla de Correo 16, Sucursal 4, (1900) La Plata (Argentina)

(Received 26 September 1988)

\section{ABSTRACT}

The surface topography of amorphous metals useful as electrocatalysts in water electrolysis, denoted as $\mathrm{G} 16\left(\mathrm{Co}_{50} \mathrm{Ni}_{25} \mathrm{Si}_{15} \mathrm{~B}_{10}\right)$ and $\mathrm{G14}\left(\mathrm{Fe}_{60} \mathrm{Co}_{20} \mathrm{Si}_{10} \mathrm{~B}_{10}\right)$, are studied at the $\mu \mathrm{m}$ scale with a conventional SEM, and at the nm scale with the STM. Both untreated specimens as well as those employed as electrodes for a relatively prolonged time exhibit the same microstructure with amorphous and crystalline surface regions. The microcrystallite reduced size structure, probably involving a very compact structure, appears to be of the greatest importance concerning the electrocatalytic activity of these materials.

\section{INTRODUCTION}

The so-called amorphous metals appear to be very promising new materials for alkaline water electrolysis [1]. Among the known crystalline materials, the cobalt containing perovskites and spinels are particularly attractive because of their excellent electrocatalytic activity for the oxygen evolution reaction. This property can be explained through the easy change of the oxidation state of cobalt [2-4]. In order to take advantage from these mixed oxide passive layers as electrocatalysts to gain stability and to avoid ageing problems, the use of amorphous metal composed of metals of the iron group, forming anodically spinel-like passive layers, was suggested $[1,5,6]$.

Despite the usefulness of these materials, whose relevant properties are, in principle, associated with their amorphous structure as derived from X-ray data [7], 
their true surface morphology at the atomic level remains obscure. However, an attempt can be made at present to solve this intriguing problem by means of scanning electron tunneling microscopy $[8,9]$.

This paper reports for the first time the surface topography at the nm level of the amorphous metals denoted as $\mathrm{G16}$ and $\mathrm{G14}$, whose compositions are $\mathrm{Co}_{50} \mathrm{Ni}_{25} \mathrm{Si}_{15} \mathrm{~B}_{10}$ and $\mathrm{Fe}_{60} \mathrm{Co}_{20} \mathrm{Si}_{10} \mathrm{~B}_{10}$, respectively [1,5]. The purpose of this research is: (i) to evaluate the extent of homogeneity of the surface; (ii) to determine the possible existence of ordered structures at the $\mathrm{nm}$ level; (iii) to investigate surface morphology changes caused by electrode performance in alkaline water electrolysis; and (iv) to estimate the average size of clusters at the surface which may be responsible directly for the electrocatalytic efficiency of these materials $[1,5,6]$. The present investigation is complemented with the corresponding SEM micrographs to cover the widest possible range of surface imaging.

\section{EXPERIMENTAL}

The amorphous metals G14 and G16 were prepared by rapid quenching by Vakuumschmelze GmbH, Hanau, F.R.G. [1]. Cobalt-nickel spinel covered nickel electrodes were prepared by thermal decomposition of the respective nitrates according to procedure described by Barendrecht and co-workers [10].

The electrochemically treated samples were polarized galvanostatically in $1 \mathrm{~mol} / 1$ $\mathrm{KOH}$ solution with an anodic current density of $0.2 \mathrm{~A} / \mathrm{cm}^{2}$ for $5 \mathrm{~h}$. During this treatment oxygen was evolved at the electrodes. For the polarization experiments a Wenking HP72 high power potentiostat was used.

Scanning electron micrographs (SEM) of the samples were obtained using imaging of secondary electrons. Primary electrons with an energy of $15 \mathrm{keV}$ were used. The scale lengths are in the figures.

STM images were taken at room temperature and atmospheric pressure with a fourth generation STM (pocket size) instrument [11]. Data were taken at a tunneling voltage of $-10 \mathrm{mV}$ (tip negative) and a tunneling current of $5 \mathrm{nA}$. A typical scanning frequency was $0.1 \mathrm{~Hz}$. Real time two-dimensional color level displays of the specimen surface were also obtained.

\section{RESULTS}

\section{SEM images}

The amorphous metals were foils of $20-50 \mu \mathrm{m}$ thickness with a width of $15 \mathrm{~mm}$. Due to the preparation procedure they show a different morphology on both side. One side looks matt, the other one blank. Figure 1 shows SEM images of both sides of the untreated G16. The line-type macroscopic structures on the matt side are probably caused by the preparation procedure. On the blank side no macroscopic structure is detectable. The material G14, shown in Fig. 2, looks quite similar to G16. SEM images of anodically treated G16 are shown in Fig. 3. No obvious 

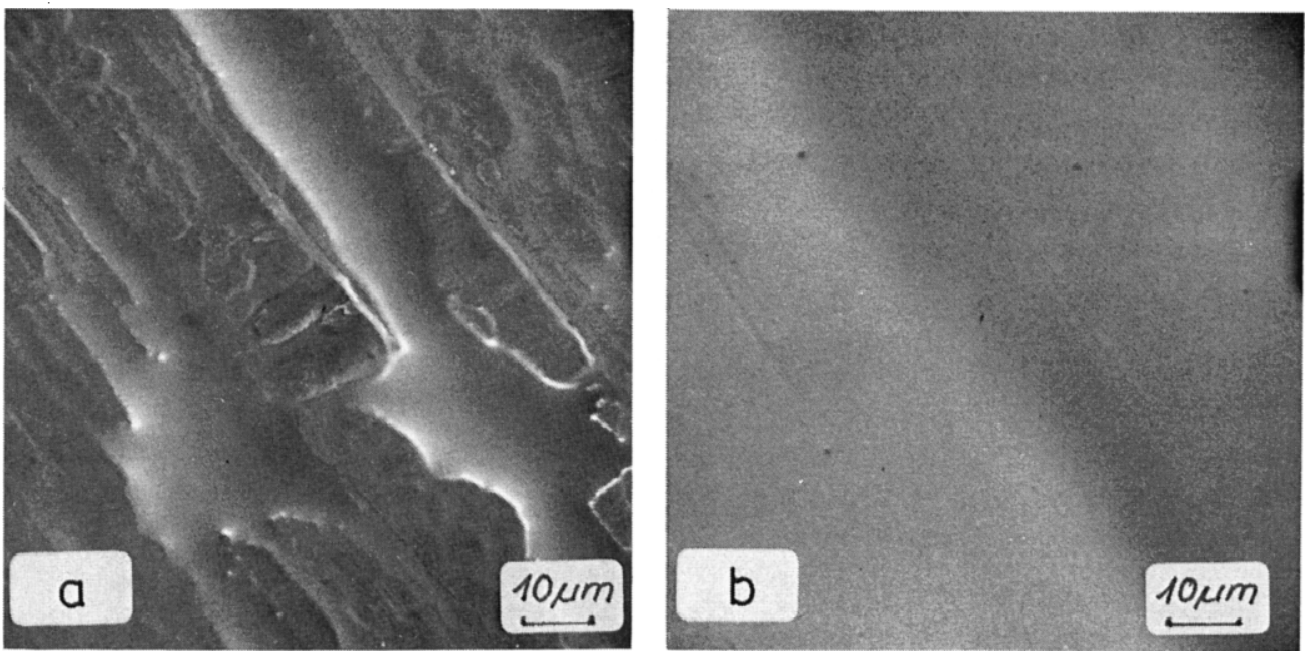

Fig. 1. SEM images of untreated G16. (a) Matt side; (b) blank side.

surface changes on the matt side can be seen, but on the blank side some small etching defects can be detected.

The spinel covered nickel shown in Fig. 4 exhibits a very rough surface and smaller and larger oxide islands. In the lower half a fraction of a larger oxide island can be seen.
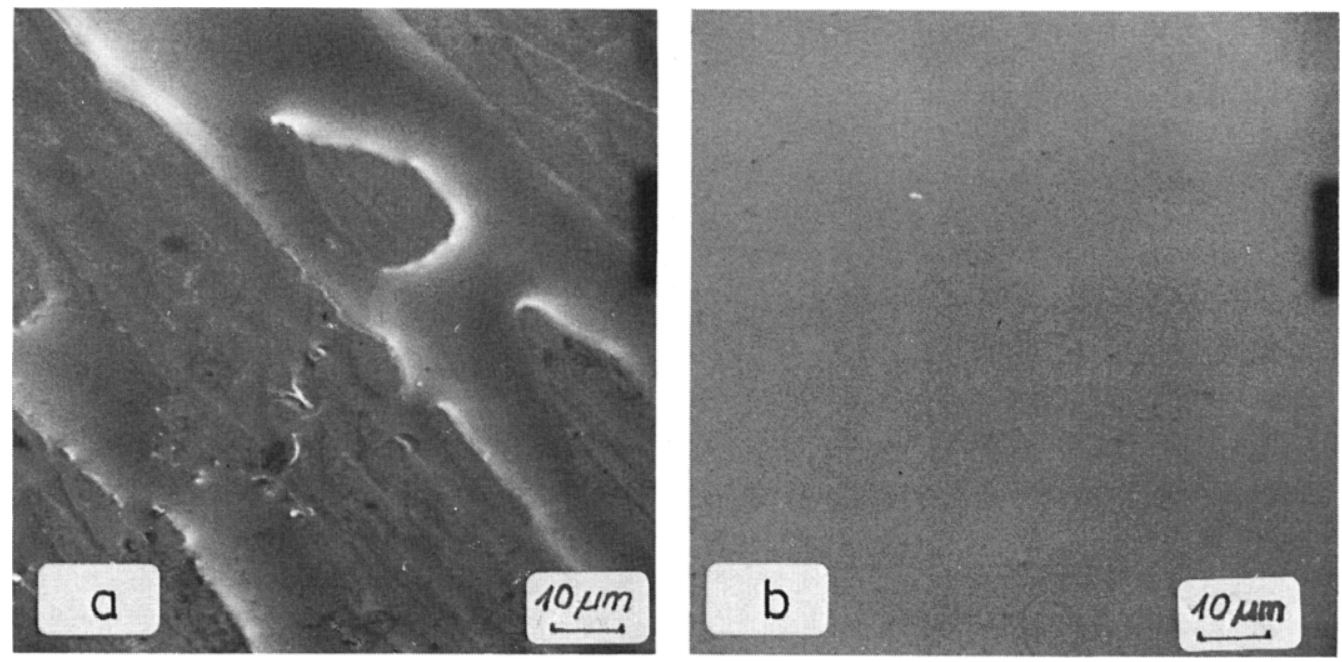

Fig. 2. SEM images of untreated G14. (a) Matt side; (b) blank side. 

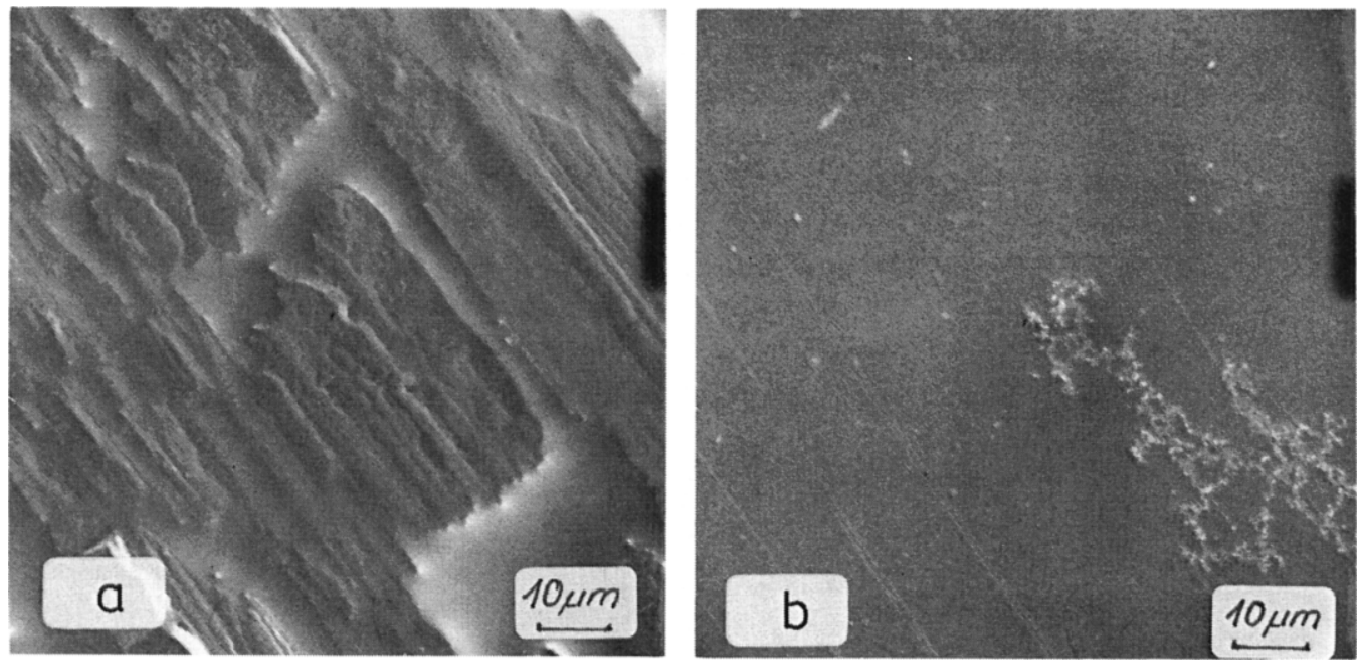

Fig. 3. SEM images of $\mathrm{G} 16$ used as anode for $5 \mathrm{~h}$ with $200 \mathrm{~mA} / \mathrm{cm}^{2}$ in $1 \mathrm{~mol} / 1 \mathrm{KOH}$. (a) Matt side; (b) blank side.

\section{STM images}

Scanning tunneling microscope (STM) images of the amorphous electrodes G16 (Figs. 5 and 6) show two characteristic regions: (i) very rough zones with high corrugation, however showing aligned structures, and (ii) flat regions of reduced size $(100 \mathrm{~nm})$. These regions form a clear stepped structure. It is interesting to note that the two regions are observed on both blanks (Figs. 5a and 6a) and treated electrodes

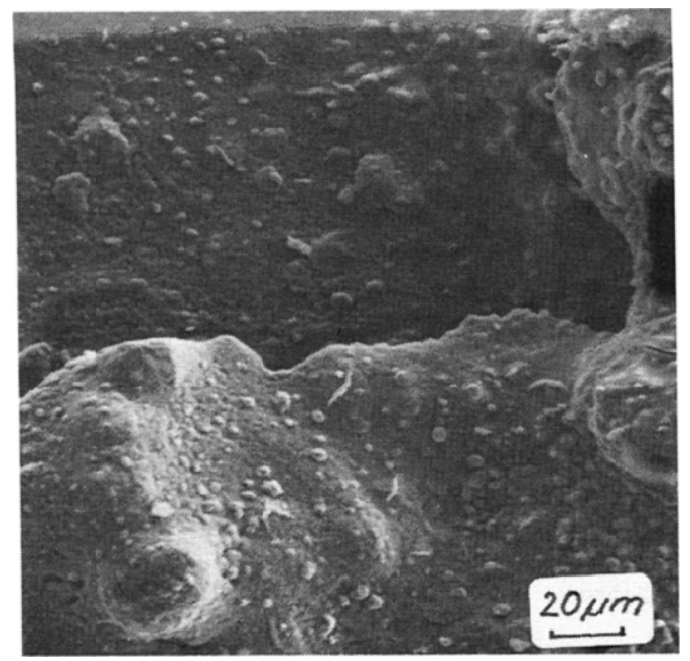

Fig. 4. SEM image of the unused spinel covered nickel electrode. 

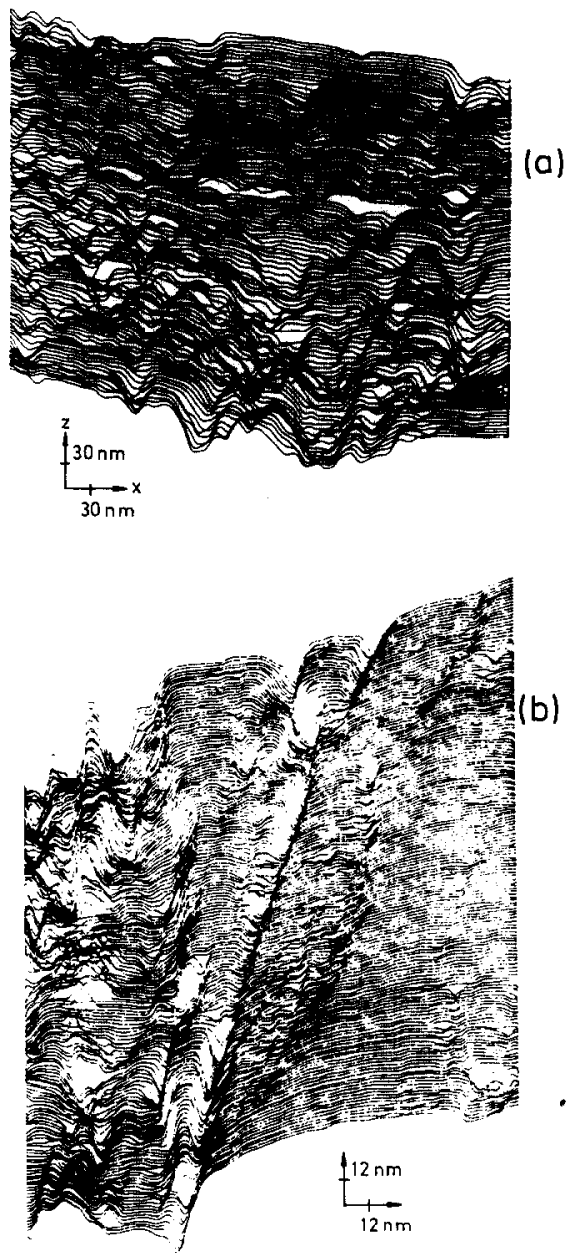

Fig. 5. STM image showing two characteristics regions: rough zones with high corrugation (up to $60 \mathrm{~nm}$ ) and flat regions in between. (a) G16 blank; (b) G16 used as anode in $1 \mathrm{~mol} / 1 \mathrm{KOH}$ at $0.2 \mathrm{~A} / \mathrm{cm}^{2}$ during $5 \mathrm{~h}$. The relative sizes change from one sample to the other. The specimen shown in (b) presents very sharp boundaries separating the two characteristic regions.

(Figs. $5 \mathrm{~b}$ and $6 \mathrm{~b}$ ). The boundaries between these two regions are sharp and well-defined, as can be seen more clearly on Figs. 6a,b. The flat microcrystalline regions apparently involve an ordered structure of terraces and steps the height of which, within the lateral resolution of the microscope, is estimated as $0.3 \mathrm{~nm}$. The flat parts of both treated and untreated electrodes show corrugations of about $1 \mathrm{~nm}$ height or perhaps lower, and 5-10 $\mathrm{nm}$ spacing which should be assigned to microcrystalline regions. The only difference which can be discerned between treated and untreated samples is the etched structure which seems to be caused by the electrochemical reaction (Fig. 7). Despite the surface etching it appears that the 

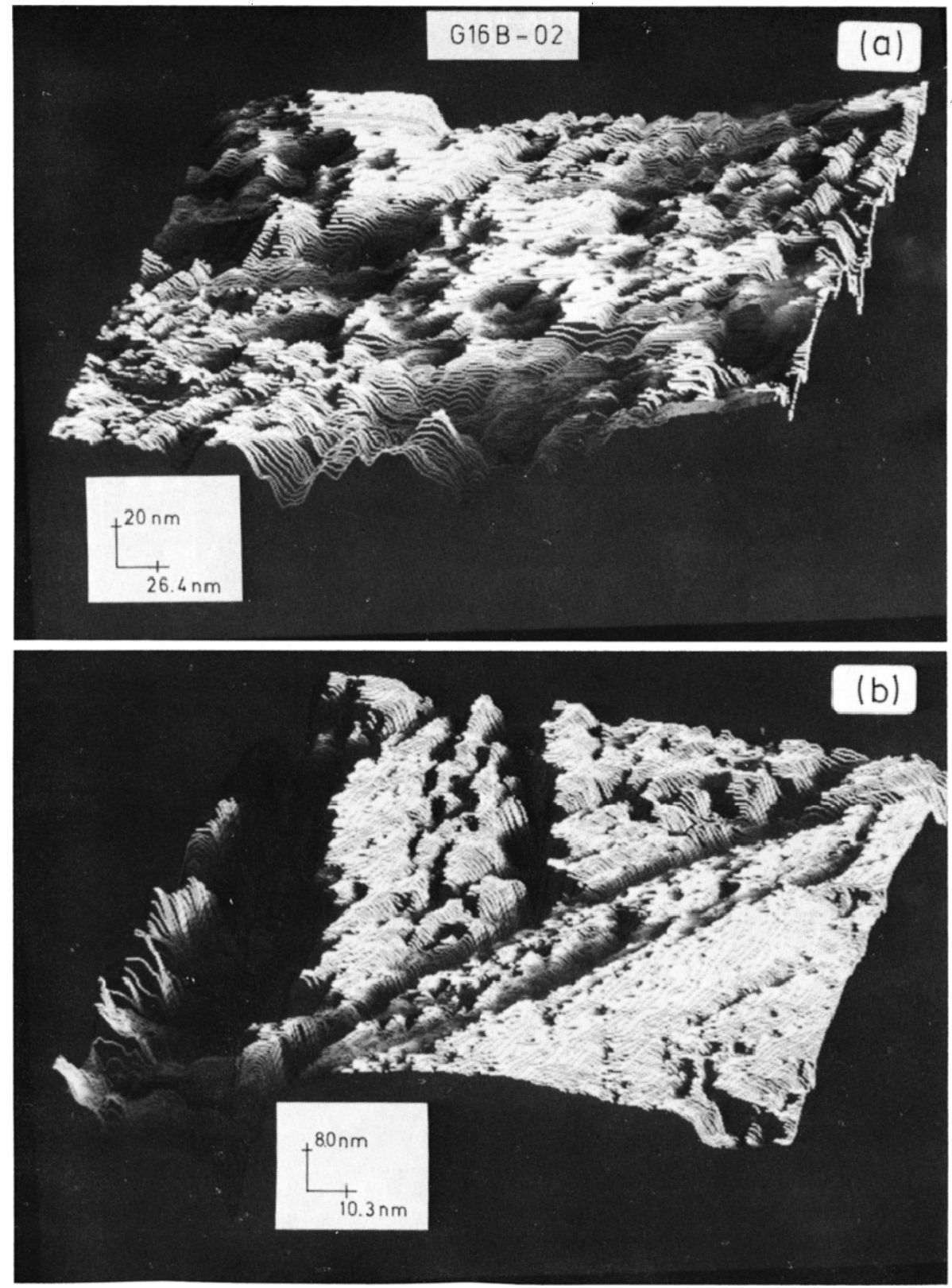

Fig. 6. STM 3-D processed images illuminated laterally. (a) G16 blank; (b) G16 used as anode in 1 mol/1 $\mathrm{KOH}$ at $0.2 \mathrm{~A} / \mathrm{cm}^{2}$ during $5 \mathrm{~h}$. The features described in Fig. 5 appear more clearly defined.

essential topographic features of the surface are maintained. The STM imaging of G14 specimens was perturbed by the formation of a surface oxide layer on both blanks and treated surfaces. 


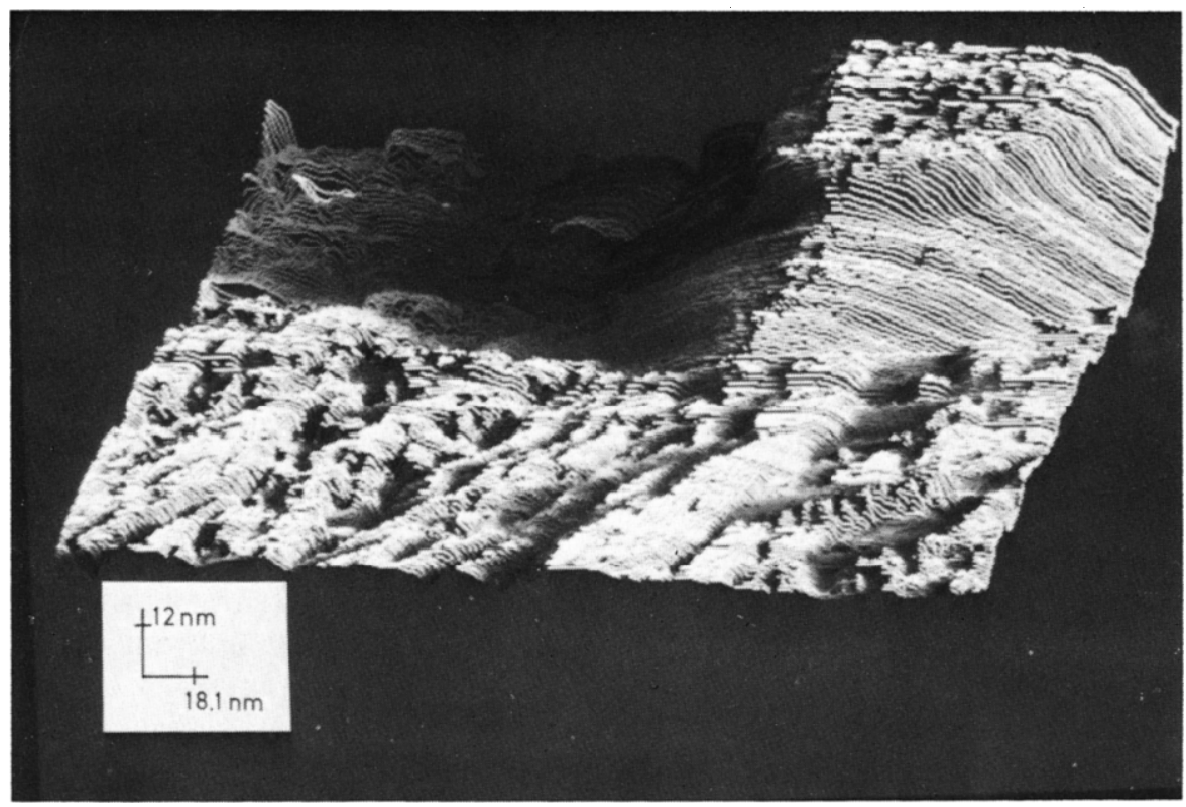

Fig. 7. STM image showing the structure appearing on the treated G16 sample, which could be produced by inhomogeneous etching of the structure during the electrochemical process.

DISCUSSION

In order to gain more information about the surface structure of the G16 specimen it should be remembered that this material ${ }_{x}$ when used as an anode in water electrolysis, undergoes an oxide layer formation of the spinel type according to the reaction:

$\mathrm{NiCo}_{2}+8 \mathrm{OH}^{-}=\mathrm{NiCo}_{2} \mathrm{O}_{4}+4 \mathrm{H}_{2} \mathrm{O}+8 e^{-}$

This reaction has been identified by comparison of cyclic voltammograms of amorphous alloys of different nickel and cobalt content [1]. A similar type of behaviour probably occurs on the G14 specimen.

It is quite likely that the $\mathrm{Ni}-\mathrm{Co}$ spinel is already formed when the untreated metal comes in contact with air during the rapid quenching preparation procedure. Therefore, it is probable that the bulk metal is actually represented by the metallic composition $\mathrm{Ni}_{25} \mathrm{Co}_{50} \mathrm{Si}_{15} \mathrm{~B}_{10}$, the outer passivating layer being formed by $\mathrm{NiCo}_{2} \mathrm{O}_{4}$ [1-6].

Previously reported data on the topography of other amorphous specimens indicated that they exhibit very flat random structures, the corrugation being lower than $1 \mathrm{~nm}$ high [11,12]. According to previous results on glassy $\mathrm{RhZr}$ [11], the flat part of the surface should correspond to the amorphous phase. Together with this phase, rough regions are found which could be assigned to a crystalline phase 
because of its ordering. Interestingly, these clear differences in the topography of amorphous and crystalline surface regions coincide with kinetic and thermodynamic data obtained recently for adsorbed hydrogen on crystalline and amorphous nickel [13]. From kinetic analysis of cathodic polarization curves the rate constants for both directions of the Tafel reaction:

$2 \mathrm{Me} \ldots \mathrm{H}_{\mathrm{ad}} \rightleftharpoons 2 \mathrm{Me}+\mathrm{H}_{2}$

could be obtained, allowing the calculation of the equilibrium constant, and from its temperature dependence, the entropy of adsorbed hydrogen atoms could be calculated. This entropy is lower than that of atomic hydrogen gas, but significantly higher for amorphous nickel as compared to crystalline nickel. The random structure of the amorphous surface should obviously offer a greater number of energetic states of the metal atoms, resulting in a higher entropy of the adsorbed hydrogen atoms. Furthermore, the temperature dependence of the symmetry factor has been evaluated as suggested by Conway et al. [14]. The clear differences in the enthalpic and entropic components of the symmetry factor for crystalline and amorphous nickel indicate different activation processes at the two surfaces which become imaginable by the different surface morphology of the two regions clearly demonstrated by the STM images shown in the present work.

As the sample is amorphous in the bulk in terms of $\mathrm{X}$-ray diffraction patterns, the crystalline phase must be confined to the passivating spinel-like layer. From the STM results, the similarity between treated and untreated samples indicates that the characteristics of the passivating layer is not changed by the electrochemical treatment. Small crystalline structures in an amorphous matrix have also been reported for glassy $\mathrm{RhZr}$ [11], although the relative size was larger and the number of crystallites smaller than in the present case. Accordingly, due to the small number of such crystallites and their small sizes, it is not possible to see clearly developed $\mathrm{X}$-ray diffraction patterns for the so-called amorphous metals. The corrugation spacing of about $5-10 \mathrm{~nm}$ indicates the existence of regions approaching a certain regular periodicity. Otherwise, the spacing and geometry of corrugations at microcrystalline domains resulting from STM real-time two-dimensional imaging (Figs. 6 and 7) fluctuates considerably, as one should expect for a system where the atomic lattices of the domains are deformed. These characteristics were already observed for amorphous $\mathrm{Pd}_{77.5} \mathrm{Cu}_{6} \mathrm{Si}_{16.5}$ alloys through high resolution electron microscopy [15].

The surface layer structure in the form of the microcrystallites is interesting in two respects. Firstly, its development results from the oxidation of the amorphous phase. These microcrystallites do not have an extended long range order and therefore the material appears amorphous. Such microcrystals in amorphous metal structures, which have already been suggested for other amorphous [16] metals, would have a very compact structure, in particular icosahedral for the case of spinel-type $\mathrm{NiCO}_{2} \mathrm{O}_{4}$ formed on G16. The crystallographic parameter of cubic face centered $\mathrm{NiCO}_{2} \mathrm{O}_{4}$ spinel is $0.8112 \mathrm{~nm}$ as derived from radiocrystallographic analysis using air as carrier gas [17]. This means that each microcrystallite would probably 
involve a few thousand spinel unit cells. The formation of such a structure should be assisted by the presence of $\mathrm{B}$ and $\mathrm{Si}$ atoms acting as hindrance for large size spinel oxide layer growth. Secondly, analysis of the STM images suggests that the electrocatalytic activity of G16 should be attributed to a combined effect of the spinel-type $\mathrm{NiCO}_{2} \mathrm{O}_{4}$ and the microcrystalline structure of the surface layer. Therefore, the catalytic activity of these electrodes due to the combined effect of composition and structure of the electrode surface layer should be related to the so-called particle size effect in heterogeneous catalysis $[18,19]$.

\section{ACKNOWLEDGEMENTS}

The present work resulted from a cooperation between the Universidad Autónoma de Madrid (Spain), the DECHEMA Institut (F.R.G.) and INIFTA, Universidad. Nacional de La Plata (Argentina), assisted financially by a grant from the VW-Stiftung (F.R.G.).

\section{REFERENCES}

1 G. Kreysa and B. Hakansson, J. Electroanal. Chem., 201 (1986) 61.

2 H. Wendt and V. Plzak, Electrochim. Acta, 28 (1893) 27.

3 J.O'M. Bockris and T. Ottagawa, J. Electrochem. Soc., 131 (1984) 131.

4 J. Haenen, W. Visscher and E. Barendrecht, J. Electroanal. Chem., 208 (1986) 273, 297, 323.

5 G. Kreysa and B. Hakansson, DECHEMA-Monogr., 102 (1986) 361.

6 K. Jüttner, W.J. Lorenz and G. Kreysa, Proceedings of the 172th ECS Meeting, 18-23 Oct. 1987, The Electrochemical Society, Pennington, NJ, 1988.

7 T. Egami, in H.-J. Güntherrodt and H. Beck (Eds.), Topics in Applied Physics, Vol. 46, Springer, Berlin, 1981 p. 25.

8 G. Binnig and H. Rohrer, Helv. Phys. Acta, 55 (1982) 726.

9 G. Binnig and H. Rohrer, Surf. Sci., 126 (1983) 236.

10 G.D. Haenen, W. Visscher and E. Barendrecht, J. Appl. Electrochem., 15 (1985) 29.

11 A.M. Baro, R. Paganini and K.W. Rao, to be published.

12 R. Wiesendanger, M. Ringger, L. Rosenthaler, H.R. Hidber, P. Oelhafen, H. Rudin and H.-J. Güntherrodt, Surf. Sci., 181 (1987) 45.

13 G. Kreysa, B. Hakansson and P. Ekdunge, Electrochim. Acta, 33 (1988) 1351.

14 B.E. Conway, D.F. Tessier and D.P. Wilkinson, J. Electroanal. Chem., 199 (1986) 249.

15 Y. Hirotsu, M. Uchara and M. Ueno, J. Appl. Phys., 59 (1986) 3081.

16 R. Wiesendanger, L. Eng. H.R. Hidber, P. Oelhafen, L. Rosenthaler, U. Staufer and H.-J. Güntherrodt, Surf. Sci., 189 (1987) 24.

17 P. Boix, Bull. Soc. Chim. Fr., (1965) 1085.

18 O.M. Poltorak and V.S. Boronin, Russ. J. Phys. Chem., 40 (1966) 1436.

19 J.R. Anderson, Structure of Metallic Catalysis, Academic Press, New York, 1975. 